\title{
GROWTH CHARACTERISTICS OF TWO SELECTED EUCALYPTUS CLONES IN RELATION TO PHYSIOLOGICAL RESPONSES
}

\author{
MANOHARAN $\mathbf{P}^{1}$ * AND N. W. PAMMENTER ${ }^{2}$ \\ ${ }^{1}$ Department of Botany, Faculty of Science, Eastern University, Vantharumoolai \\ Sri Lanka, \\ ${ }^{2}$ School of Life and Environmental Sciences, University of KwaZulu-Natal, \\ Durban 4041, South Africa
}

* Corresponding author (E-mail: prikok@yahoo.com)

\begin{abstract}
The water relations, leaf gas exchange characteristics, xylem cavitation, and root-shoot hydraulic conductances of two Eucalyptus clones grown at a mesic site were assessed when they were three months old to reveal whether there are any clonal differences in growth rates which are related to the plant physiological characteristics. Soil water potential $\left(\Psi_{\text {soil }}\right)$, assessed as predawn leaf water potential $\left(\Psi_{\mathrm{PDL}}\right)$, showed that the compartment supporting clone TAG14 had higher $\Psi_{\text {soil }}(-0.12$ $\mathrm{MPa})$ than the compartment supporting clone GU210 $(-0.20 \mathrm{MPa})$. Diurnal values of leaf water potential $\left(\Psi_{\mathrm{L}}\right)$, net photosynthesis $(\mathrm{A})$, transpiration rate $(\mathrm{E})$ and stomatal conductance $\left(\mathrm{g}_{\mathrm{s}}\right)$ were consistently higher in TAG14 than in GU210. Midday $\Psi_{\mathrm{L}}$ in TAG14 was $-1.59 \mathrm{MPa}$ while in GU 210 it was $-1.85 \mathrm{MPa}$. However, this difference was not statistically significant. Ultrasonic acoustic emission (UAE) indicated by maximum events per hour $\left(\mathrm{EPH}_{\max }\right)$ and threshold water potential corresponding to the initiation of rapid cavitation ( $\psi_{\mathrm{CAV}}, \mathrm{cUAE} \%$ ) showed that TAG14 is more prone to xylem cavitation than GU210 and this could lead to a reduction in $\mathrm{g}_{\mathrm{s}}$ in GU210 from midmorning onwards. Use of a high pressure flow meter (HPFM) showed that the root conductance per unit leaf area $\left(\mathrm{K}_{\mathrm{r} / \mathrm{LA}}\right)$ was higher in TAG14 than in GU210, whereas, shoot conductance per unit leaf area and shoot dry weight $\left(\mathrm{K}_{\mathrm{S} / \mathrm{A},}, \mathrm{K}_{\mathrm{S} / \mathrm{sdw}}\right)$ were higher in GU210 than in TAG14. Whole plant conductances, expressed per unit leaf area $\left(\mathrm{K}_{\mathrm{P} / \mathrm{LA}}\right)$ were higher in TAG14 than in GU210. However, all the physiological measurements were consistent with the hypothesis that higher hydraulic conductances as observed in TAG14 leading to lower leaf level water stress and higher photosynthetic rates. Above ground biomass of TAG14 was also higher than that of GU210, which is in agreement with this hypothesis.
\end{abstract}

Keywords: Eucalyptus spp clones, leaf physiology, stem xylem cavitation, root-shoot hydraulic conductances, growth. 


\section{INTRODUCTION}

The fast growth of Eucalyptus spp. and the increased demand for wood, essential oils, honey, pulpwood, fiberboard, tanning materials, decorations, windbreaks and many other miscellaneous uses in South Africa, South America and Indonesia have resulted in a steady increase in the extent of these plantations despite the fact that Eucalyptus spp. are known to consume large quantities of water (van Wyk, 1990; Le Roux \& Van Staden, 1991). Plant productivity requires photosynthetic $\mathrm{CO}_{2}$ fixation and water is a major limiting factor for photosynthesis in many environments (Kramer \& Boyer, 1995). Demands by the forestry industry for increased productivity and the introduction of Eucalyptus spp. into marginal areas have created a need for a detailed understanding of the water relations of commercially grown Eucalyptus clones (Mulin \& Park, 1992). However, the growth and distribution of Eucalyptus spp are limited by climatic constraints such as temperature and water availability (Sommer \& Wetzstein, 1984). In South Africa, the main factor limiting forestry expansion is the inadequate rainfall (Olbrich et al., 1993). The drought has caused severe mortality of some Eucalyptus clones, whereas other clones had survived the drought (Vander Willigen \& Pammenter, 1998). Such losses have raised concern for improving silvicultural practices by selecting Eucalyptus clones that would not only survive but also continue to be productive under restricted water conditions (Olbrich et al., 1993). Such clones need to be assessed physiologically under different conditions.

The hydraulic architecture of a plant can limit water flow to the leaves and thus it can limit leaf water potential, stomatal opening and gas exchange (Tyree \& Ewers, 1996). The vulnerability of xylem to cavitation may change the efficiency of the hydraulic architecture because cavitation in the xylem increases the hydraulic resistances (Tyree \& Sperry, 1989; Sperry \& Pockman, 1993). In response to xylem embolisms, steeper water potentials in the xylem exist and these can lead to stomatal closure. Such closure reduces both loss of water and uptake of carbon dioxide so that carbon assimilation by leaves decreases in the water stressed plants (Becker et al., 2000). Ryan \& Yoder (1997) hypothesized the hydraulic limitation in old and tall trees, where increasing axial hydraulic resistances decreased the stomatal conductances, lead to lower net $\mathrm{CO}_{2}$ uptake, resulting in the poor growth. However, several studies have revealed that differences in hydraulic conductances could affect photosynthesis through affecting gas exchange (Mencuccini \& Grace, 1996; Hubbard et al., 1999) and hence could affect the growth of the plants (Schultz \& Mathews, 1988). 
Growth characteristics

Several studies on the hydraulic architecture of fast and tall growing Eucalyptus species and hybrid clones have been carried out. Franks et al. (1995), Vander Willigen \& Pammenter (1998), Brodribb \& Field (2000) and Clearwater \& Meinzer (2001) measured hydraulic conductances in stems and branches. Some researchers demonstrated a good relationship between some parts of the above ground hydraulic architecture and the leaf photosynthetic capacity (Brodribb \& Field, 2000). The relationships between root hydraulic architecture and leaf physiology or the role of roots as a component of whole plant hydraulic architecture are still unknown. Becker et al. (2000) suggested that observations of the whole plant are more pertinent than those at the branch level for determining transport sufficiency of water and solutes to leaves.

During the present study, the physiological characteristics of three month old plants of two Eucalyptus clones grown in a mesic site were investigated. An advantage of studying young field grown saplings is that root restrictions will not affect physiological parameters and growth as in potted saplings. The main objectives of the present study were to assess the interrelations between hydraulic architecture and plant water relations, including xylem cavitation, and leaf gas exchange. Additionally, as most of the experimental work described in literature was carried out on potted plants, the field-grown material could act as a bench-mark to determine whether root restriction in pots significantly influences the hydraulic and physiological characteristics.

\section{MATERIALS AND METHODS}

Field studies were conducted on a Eucalyptus grandis x E. urophylla clone (GU210) and a pure Eucalyptus grandis clone (TAG14). Saplings, which were growing on mesic sites with a mean annual rainfall of $1280 \mathrm{~mm}$ at an espacement of $2.1 \times 3.1 \mathrm{~m}$ were used for the study. Measurements were made in August 2001 on randomly selected plants with an average height of $0.60 \mathrm{~m}$. There was no rainfall during the study period. The location of the sites (compartments) were $28^{\circ} 35^{\prime} 32^{\prime \prime} \mathrm{S}$, $32^{\circ} 04^{\prime} 21^{\prime \prime} \mathrm{E}$ (clone GU210, Rattrays, soil type: Hutton Hu 2200) and (28 $41^{\prime} 11^{\prime \prime} \mathrm{S}$, $32^{\circ} 03^{\prime} 25^{\prime \prime} \mathrm{E}$ (clone TAG14, Nseleni, soil type: Fernwood). For each set of experiments, 8 replicates were used. Physiological parameters between the two clones were statistically compared using the Statistical Package for Social Sciences (SPSS) for Windows. The slopes of the relationship between transpiration and the leaf water potential for the clones were statistically compared using the GraphPad Prism, version 3.02 package. 


\section{Leaf water potential $\left(\Psi_{l}\right)$ and gas exchange}

Leaf water potentials $\left(\Psi_{\mathrm{L}}\right)$, equivalent to xylem water potentials were measured from pre-dawn to $14.00 \mathrm{~h}$ using a Scholander pressure chamber (Scholander et al., 1965) to reveal diurnal pattern of soil-plant water status. At each measurement time 8 to 14 leaves each from a separate plant were sampled. Net photosynthesis rate $(\mathrm{A})$, transpiration rate $(\mathrm{E})$ and stomatal conductance $\left(\mathrm{g}_{\mathrm{s}}\right)$ of healthy leaves from the center of the outer edge of the canopy were measured using a portable photosynthesis system (model LI-6400, Li-Cor, Inc., Lincoln, NE, U.S.A). After these measurements, the leaves were excised for water potential measurements in a pressure chamber. This was repeated on four plants, with one leaf per plant, with ten measurements being taken during the course of the day, from $07.00 \mathrm{~h}$ to $14.00 \mathrm{~h}$. All measurements were repeated on the following day.

\section{Stem xylem cavitation detected by an $U A E$}

Xylem cavitation events in main stems were measured on three replicates of each clone using an ultrasonic acoustic emission (UAE) detector using an ultrasonic sensor (model I15I, Physical Acoustic Corp., Princeton, N J, USA) and preamplifier (model 4615, Physical Acoustic Corp., Princeton, NJ, USA) sold as a drought stress monitor. The sensor was clamped to the main stem, $0.1 \mathrm{~m}$ above ground and below the branches. The sensor was attached to the stem on the evening prior to measurement and was connected to the drought stress monitor (adjusted to a setting of 72 decibels) on the following morning and emissions were recorded from $07.00 \mathrm{~h}$ to $15.00 \mathrm{~h}$. Concurrently with recording of xylem cavitation events, gas exchange and water potentials were also measured on a single leaf on ten occasions during the course of the day. Cumulated events (CE) and events per hour (EPH) were recorded at 60 minute intervals. EPH were plotted against time, and as concurrent leaf water potentials were measured, EPH could be plotted as a function of leaf water potential. Also, cumulated UAE were expressed as a percentage of the first plateau maximum corresponding to the cumulative number of UAE recorded at the time, as described by Salleo et al. (2000). The percentage of cumulated UAE (cUAE\%) was also plotted against water potential, which was recorded concurrently.

\section{Root pressures $\left(P_{r}\right)$ and Root - shoot hydraulic conductances}

Root pressure was measured in 8 - 10 replicates by attaching manometers to decapitated root stump. The length of the air column was recorded at $06.00 \mathrm{~h}$ and $12.00 \mathrm{~h}$ and root pressure was expressed in $\mathrm{kPa}$ above atmospheric pressure.

Root and shoot hydraulic conductances were measured in eight replicates using a high pressure flow meter (HPFM) in the transient and quasi-steady state 


\section{Growth characteristics}

modes, respectively as described by Tyree et al. (1994b; 1995) and Yang \& Tyree (1994). In the field studies, root conductances were not measured on plants previously sampled for root pressure as adequate material was available. For each measurement of root conductance $\left(\mathrm{K}_{\mathrm{r}}\right)$, the average of three transients were taken. In the shoots, total shoot conductance $\left(K_{S}\right)$, leaf resistance $\left(R_{L}\right)$, petiole resistance $\left(R_{P}\right)$, resistance of leaf bearing branches $\left(R_{L B B}\right)$ and main stem resistance $\left(R_{M S}\right)$ were measured after sequentially excising the respective plant components. Total leaf area from each shoot was measured using a leaf area meter and the dry weight of leaves, petioles and stems were measured after oven drying at $60^{\circ} \mathrm{C}$ for 48 hours. Drying temperature was determined by trial and error studies on different Eucalyptus spp. samples. The height from the stem base from the soil surface to the apical bud and over-bark stem diameter at $0.1 \mathrm{~m}$ above from soil surface were measured on 15 randomly chosen samples of each clone.

\section{RESULTS}

\section{Clonal differences in above-ground growth and biomass allocation}

The above-ground parameters of the two clones are shown in Table 1. Shoot growth over the three months since planting, measured as height, stem over-bark diameter and total shoot biomass, as well as the biomass of the individual components, were significantly higher in TAG14 than in GU210 $(\mathrm{p}<0.05)$. The leaf area ratio (LAR, leaf area/shoot dry mass) and specific leaf area (SLA, leaf area/leaf dry mass) were lower in TAG14 than in GU210 $(\mathrm{p}<0.05)$. The total leaf area did not significantly differ between the clones. 
Table 1 - Growth parameters (Mean \pm SE) of two 3 month-old Eucalyptus clones grown in commercial plantations at mesic sites. $(n=8)$. For each parameter, different superscript letters indicate significant differences between the clones $(p<0.05)$.

\begin{tabular}{|l|c|c|}
\hline \multicolumn{1}{|c|}{ Growth parameters } & GU210 & TAG14 \\
\hline Height, $(\mathrm{m})$ & $0.53 \pm 0.01^{\mathrm{a}}$ & $0.68 \pm 0.02^{\mathrm{b}}$ \\
\hline Stem over-bark diameter $(\mathrm{mm})$ & $9.58 \pm 0.47^{\mathrm{a}}$ & $10.94 \pm 0.34^{\mathrm{b}}$ \\
\hline Total Leaf area, $\left(\mathrm{m}^{2}\right)$ & $0.61 \pm 0.07^{\mathrm{a}}$ & $0.68 \pm 0.09^{\mathrm{a}}$ \\
\hline Specific leaf area, $\left(\mathrm{m}^{2} \mathrm{~kg}^{-1}\right)$ & $19.52 \pm 0.64^{\mathrm{a}}$ & $15.04 \pm 0.67^{\mathrm{b}}$ \\
\hline Leaf weight ratio & $0.62 \pm 0.03^{\mathrm{a}}$ & $0.55 \pm 0.01^{\mathrm{b}}$ \\
\hline Leaf area ratio, $\left(\mathrm{m}^{2} \mathrm{~kg}^{-1}\right)$ & $12.17 \pm 0.70^{\mathrm{a}}$ & $8.25 \pm 0.52^{\mathrm{b}}$ \\
\hline Leaf dry mass, $(\mathrm{g})$ & $31.27 \pm 3.59^{\mathrm{a}}$ & $44.38 \pm 4.89^{\mathrm{b}}$ \\
\hline Stem, petiole dry mass, $(\mathrm{g})$ & $19.02 \pm 2.62^{\mathrm{a}}$ & $36.37 \pm 3.45^{\mathrm{b}}$ \\
\hline Total shoot dry mass, $(\mathrm{g})$ & $50.30 \pm 5.50^{\mathrm{a}}$ & $80.75 \pm 8.18^{\mathrm{b}}$ \\
\hline
\end{tabular}

\section{Leaf water potential $(\Psi)$}

If predawn leaf water potential $\left(\Psi_{\mathrm{PDL}}\right)$ can be taken as a measure of soil water potential $(\Psi \mathrm{s})$, clone TAG14 had a higher soil water potential $(-0.12 \pm 0.01 \mathrm{MPa})$ than the clone GU210 $(-0.20 \pm 0.03 \mathrm{MPa})(\mathrm{p}<0.05)$. However, the differences in the soil types could have given rise to slightly higher water retention values in the TAG14 clone. Midday values of $\psi_{\mathrm{L}}$ were higher in TAG14 $(-1.56 \pm 0.03 \mathrm{MPa}, \mathrm{n}=8)$ than in GU210 $(-1.69 \pm 0.04 \mathrm{MPa}, \mathrm{n}=8)(\mathrm{p}<0.05)$.

\section{Diurnal patterns of leaf water potential and gas exchange}

Leaf water potentials declined from predawn to about $11.00 \mathrm{~h}$. The values in TAG14 were consistently higher than those in GU210 (Fig. 1A), and these differences were significant from $09.00 \mathrm{~h}$ to $12.00 \mathrm{~h}(\mathrm{p}<0.05)$. After about $11.00 \mathrm{~h}$, water potentials stabilised, probably because transpiration was no longer increasing.

During the morning, rates of net $\mathrm{CO}_{2}$ assimilation were marginally higher in TAG14 than in GU210 (Fig. 1B), although by midday differences were not significant $(\mathrm{p}>0.05)$. However, midday stomatal conductances (Fig. 1C) and transpiration rates (Fig. 1D) were significantly higher in TAG14 than in GU210 $(p>0.05)$. The exceptionally high stomatal conductances measured in the early morning are probably a consequence of dew deposition. Stomatal conductances reached maximum values at about $10.00 \mathrm{~h}$ (Fig. 1C), before maximum radiation 
Growth characteristics
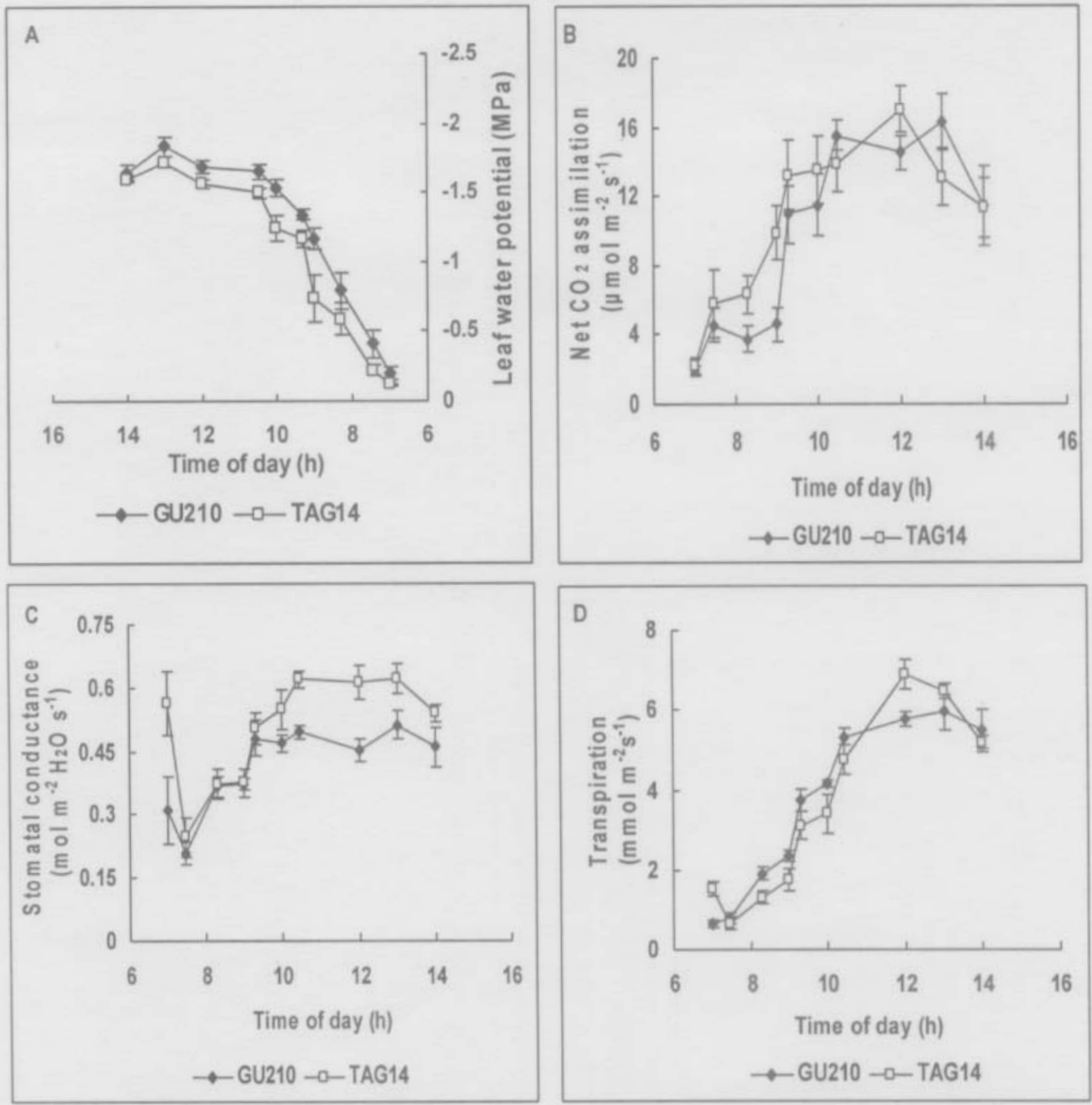

Fig. 1 Diurnal variations in instantaneous leaf water potential (A), net $\mathrm{CO}_{2}$ assimilation rate (B), stomatal conductances (C) and the transpiration (D) in two, 3 month old Eucalyptus . clones grown in the field at a mesic site. Error bars represent the \pm SEM $(n=8)$. 
intensities and temperatures (data not shown), suggesting stomatal limitation of transpiration reducing the onset of water stress. The higher values of stomatal conductance $\left(\mathrm{g}_{\mathrm{s}}\right)$ and transpiration (E) in TAG14 were associated with higher leaf water potentials, suggesting differences in hydraulic characteristics between the clones. Therefore, leaf water potentials were plotted as a function of transpiration rates, up to the point of maximum transpiration rate (Fig. 2). The relationship in TAG14 was statistically significant $(\mathrm{p}<0.05)$ suggesting that hydraulic resistance in this clone declined with increasing transpiration rates. The slope of the regression for GU210 was slightly steeper than that for TAG14. Although this difference in slopes is not statistically significant $(\mathrm{p}>0.05)$, the results do indicate that the transpiration pathway could offer somewhat less hydraulic resistance in TAG14 than in GU210.

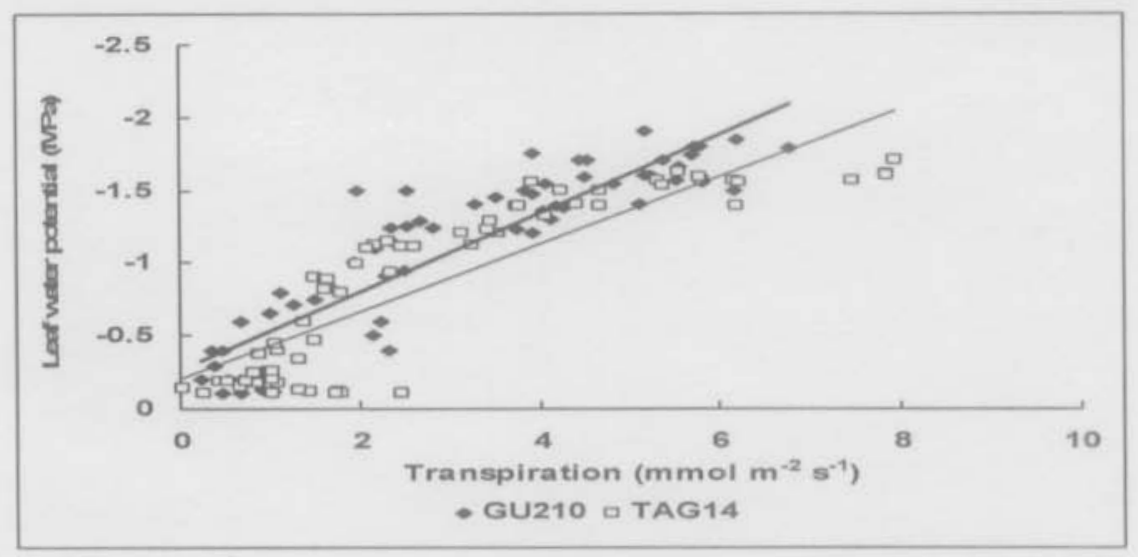

Fig. 2 The relationship between leaf water potential and transpiration rate for 3 months old saplings of Eucalyptus clones GU210 and TAG14 grown at mesic site in the field. The equations of the fitted linear regressions are $y=-\mathbf{0 . 2 6 9 1 x}$ 0.2655 for GU210 (bold line) $\left(R^{2}=0.81 ; p=0.00\right)$ and $y=-0.2319 x-0.201$, for TAG14 clone (thin line) $\left(\mathrm{R}^{2}=0.75 ; \mathrm{p}=0.00\right)$.

\section{Ultrasonic acoustic emission detection of xylem cavitation}

Only a small number of UAE events accumulated in both clones in the early morning, with acoustic events accumulating rapidly during mid-morning and levelling off after midday (Fig. 3A). Total accumulated events in GU210 was more than twice of the total accumulated events in TAG14. The data are expressed in Fig $3 \mathrm{C}$ as events per hour, together with corresponding stomatal conductances and water potentials. Cavitation increased progressively in both clones with decreasing xylem water potential from morning to midday. Maximum rates of cavitation in both clones 
Growth characteristics

occurred at mid-morning, with higher rates in GU210 (4216 EPH) than in TAG14 (1382 EPH). The water potentials corresponding to these maximum rates $(-1.55 \mathrm{MPa}$ and $-1.49 \mathrm{MPa}$, respectively) were not significantly different ( $\mathrm{p}>0.05)$.
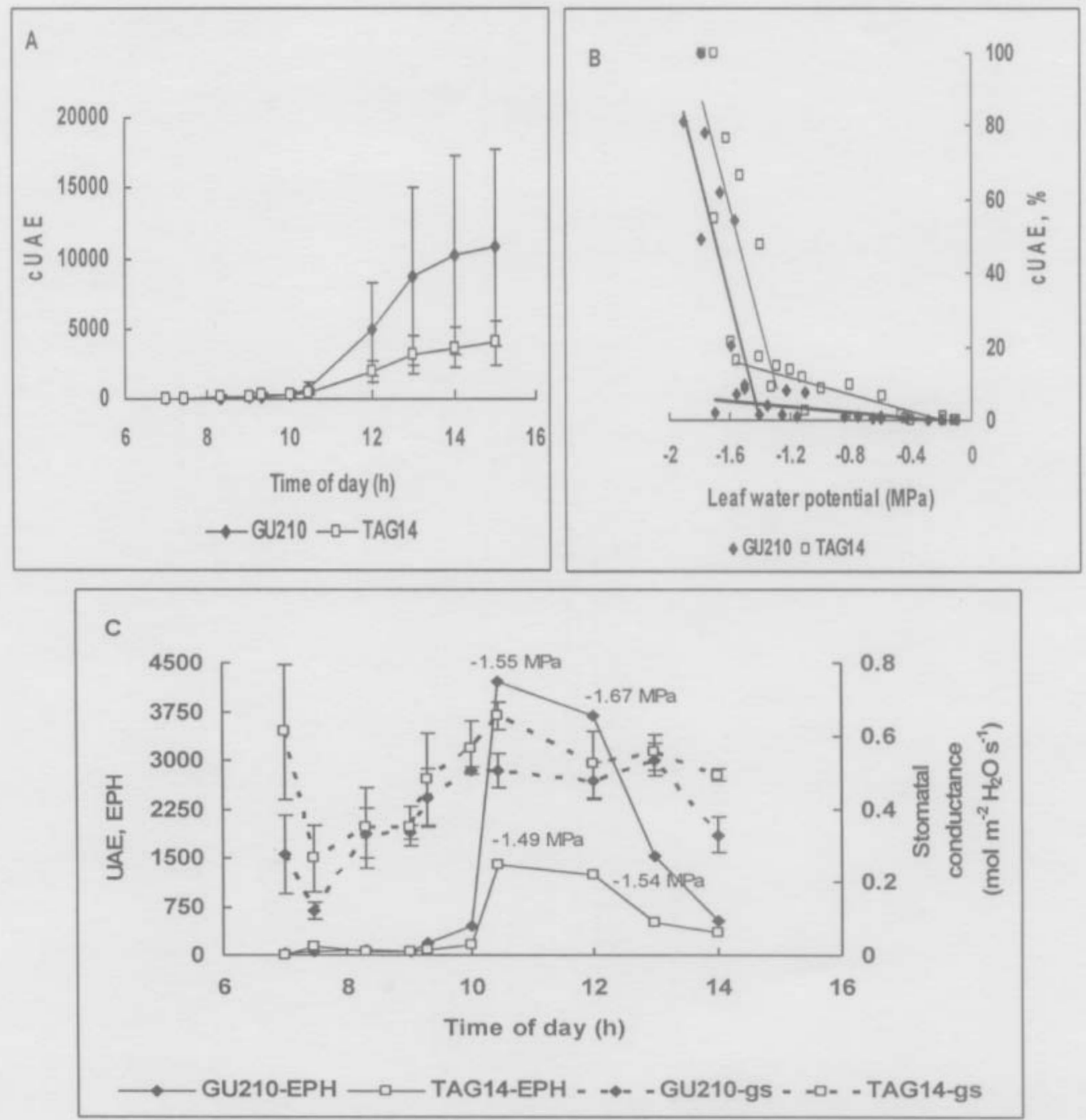

Fig. 3: - A: Xylem cavitation events measured as cumulative ultrasonic acoustic emissions (cUAE) from $07.00 \mathrm{~h}$ to $15.00 \mathrm{~h}$; B: cumulated ultrasound acoustic emission expressed as percentage of the maximum (cUAE,\%) in the main stems, plotted as a function of leaf water potential ; C: concurrently measured ultrasonic emission events per hour (UAE, EPH), with leaf water potentials and stomatal conductances ( $g_{s}$ ) in 3 months old saplings of Eucalyptus clones GU210 and TAG14 grown at a mesic site in the field. Error bars represent the \pm Standard Error of the Mean $(n=3)$. 
In both clones there was a decrease in stomatal conductance from $10.00 \mathrm{~h}$ to $12.00 \mathrm{~h}$, but the proportional decline was greater in TAG14 $(20 \%)$ than in GU210 (7\%). Although water potential continued to decline between $10.00 \mathrm{~h}$ and $12.00 \mathrm{~h}$, and cavitation events continued, the decline in water potential was less in TAG14 (3\%) than in GU210 (8\%). This was probably a consequence of the greater proportional decline in $\mathrm{g}_{\mathrm{s}}$ in TAG14. The decline in the rate of acoustic emissions was similar in the two clones ( $10 \%$ for TAG14 and $12 \%$ for GU210). The data presented in Fig. 3C suggest that the stomata of TAG14 are more sensitive to water potential than those of GU210. The decrease in $g_{s}$ in TAG14 was greater than in GU210, although the corresponding water potentials were similar (-1.49 $\mathrm{MPa}$ in TAG14, and $-1.55 \mathrm{MPa}$ in GU210).

Cumulated acoustic events were expressed as percentages of the maximum cUAE and plotted against water potential (Fig. 3B). If an arbitrary cavitation threshold is accepted as the water potential corresponding to the accumulation of 5 $10 \%$ of the maximum acoustic emissions (Salleo et al., 2000; Nardini et al., 2001), the initiation of critical water potential triggering xylem cavitation ( $\left.\psi_{\mathrm{CAv}}, \mathrm{cUAE}, \%\right)$ was $-1.38 \pm 0.10 \mathrm{MPa}$ (SEM) for GU210 and $-0.93 \pm 0.18 \mathrm{MPa}$ (SEM) for TAG14 (calculated as the mean of the water potentials corresponding to acoustic emissions between $5 \%$ and $10 \%$ of the total). These were significantly different from each other $(\mathrm{p}<0.05)$. However, visual inspection of the data indicated that a marked increase in accumulation of acoustic events occurred at water potentials lower than these. Regression lines were fitted to the data points corresponding to low cumulative events $(<20 \%)$, and to the data points corresponding to high cumulative events $(>40 \%)$. The intersection of these two lines gives the water potential at which a marked accumulation of events occurred, and could be taken as a less arbitrary indicator of the threshold water potential generating substantial cavitation events. The values of the critical thresholds estimated by this way were $-1.42 \mathrm{MPa}$ for GU210 and $-1.32 \mathrm{MPa}$ for TAG14, indicating that the stem xylem of TAG14 is more vulnerable to cavitation than that of GU210.

\section{Root pressure $\left(P_{r}\right)$}

De-topped stumps of both clones showed positive $\mathrm{P}_{\mathrm{r}}$ both overnight and at midday. The overnight $P_{r}$ of GU210 (41 kPa) was higher than that of TAG14 (28 $\mathrm{kPa})$. This difference was marginally significant $(\mathrm{p}=0.055) . \mathrm{P}_{\mathrm{r}}$ at midday was higher than the overnight value in both clones $(62 \mathrm{kPa}$ in GU210 and $53 \mathrm{kPa})$. In TAG14, however, this difference was not significant $(p>0.05)$. In TAG 14, the $P_{r}$ values at 
Growth characteristics

night were significantly different from $\mathrm{P}_{\mathrm{r}}$ values in midday $\mathrm{p}=0.005$ ). However, no such difference was noted in GU210 $(\mathrm{p}=0.080)$.

\section{Hydraulic conductances in the root, shoot and whole plant}

Absolute root hydraulic conductances $\left(\mathrm{K}_{\mathrm{r}}\right)$ in TAG14 (10.30 \pm 1.12$)$ were significantly higher than those of GU210 $(5.21 \pm 0.57)(\mathrm{F}=18.47, \mathrm{p}=0.001)$, whereas the shoot conductances $\left(\mathrm{K}_{\mathrm{S}}\right)$ of TAG14 $(14.80 \pm 1.68)$ were significantly lower than those of GU210 $(22.50 \pm 2.29)(\mathrm{p}=0.011)$. However, hydraulic conductances are more meaningful if normalised to some measure of plant size (Tyree et al. 1998). Thus the data were expressed as shoot conductance per unit leaf area $\left(\mathrm{K}_{\mathrm{S} / \mathrm{LA}}\right)$ (Tyree et al. 1998; Nardini \& Tyree, 1999), shoot conductance per unit total shoot dry weight $\left(\mathrm{K}_{\mathrm{S} / \mathrm{sdw}}\right)$ (Tyree et al.1998) and whole plant conductance per unit leaf area (K $\left.\mathrm{K}_{\mathrm{P} / \mathrm{LA}}\right)$ (Tyree $e t$ al. 1998). Whole plant conductance was calculated as $K_{\mathrm{P}}=1 /\left(1 / \mathrm{K}_{\mathrm{S}}+1 / \mathrm{K}_{\mathrm{r}}\right)($ Tyree et al. 1998). Root conductances were not normalised to the amount of root because of the difficulty of excavating roots of numerous individuals in the field.

$\mathrm{K}_{\mathrm{r} / \mathrm{LA}}$ of GU210 was significantly lower than that of TAG14 ( $\left.\mathrm{p}=0.001\right)$, but $\mathrm{K}_{\mathrm{s} / \mathrm{LA}}$ of GU210 was significantly higher than that of TAG14 ( $\mathrm{p}=0.007$ ) (Fig. 4A). Similarly, $\mathrm{K}_{\mathrm{s} / \mathrm{sdw}}$ was higher in GU210 than in TAG14 ( $\mathrm{F}=79.40$, $\mathrm{p}=0.000$ ) (Fig. 4B). The pattern of differences between the clones (higher shoot but lower root conductances in GU210, and the converse in TAG14) was such that whole plant hydraulic conductances ( $\mathrm{K}_{\mathrm{P} / \mathrm{LA}}$, Fig. 4C) did not differ significantly at the $5 \%$ level, although the difference was significant at the $10 \%$ level (GU210 $-7.25 \times 10^{-5} \mathrm{~kg} \mathrm{~s}^{-1}$ $\mathrm{MPa}^{-1} \mathrm{~m}^{-2}$; TAG14 $-9.39 \times 10^{-5} \mathrm{~kg} \mathrm{~s}^{-1} \mathrm{MPa}^{-1} \mathrm{~m}^{-2} ; \mathrm{F}=3.30, \mathrm{p}=0.089$ ). Because the leaf areas of the clones were similar (Table1), normalising shoot and root conductances by the leaf area supplied yielded values in the same relationship as the absolute values. This could be taken to suggest that the clones were not adjusting their leaf areas in relation to their hydraulic sufficiency, possibly because they were growing in mesic sites. However, despite the marked differences at the root and shoot level, whole plant conductances were similar, indicating that adjustment of leaf area was not necessary (Table 1). 

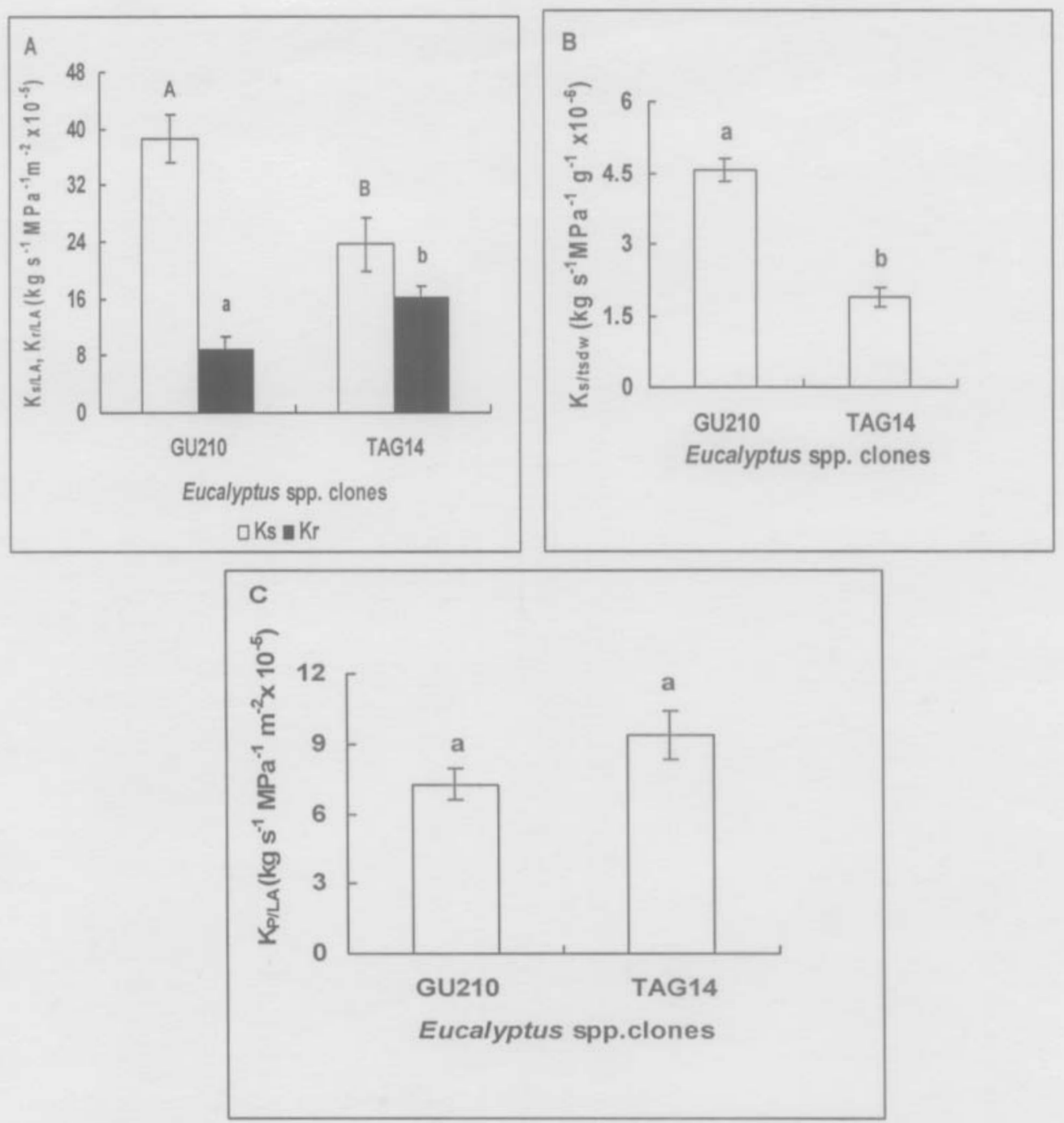

Fig. 4 - Hydraulic conductances measured for 3 month old saplings of the clones GU210 and TAG14 grown at a mesic site in the field. (A) - $K_{r}$ and $K_{s}$ expressed per unit leaf area ; (B) - $\mathrm{K}_{\mathrm{s}}$ expressed per unit total shoot dry mass basis ; (C) $K_{P}$ expressed per unit leaf area basis. Error bars represent the $\pm \operatorname{SEM}(n=8)$. Different capital letters $\left(K_{s / L A}\right)$, and small letters $\left(K_{r / L A}\right)$ in $(A)$, and small letters in $B$ and $C$ indicate significantly different values at $p<0.05$. 
Growth characteristics

\section{The components of whole plant resistances}

The hydraulic resistances of the shoots (data not shown) of TAG14 normalised to leaf area were significantly higher than those of GU210 $(p=0.004)$. Most of the shoot resistance $\left(R_{S}\right)$ was contributed by the leaves $\left(R_{L}\right)$, which includes both vascular and non-vascular components. The leaf resistance of TAG14 was significantly higher than that of GU210 ( F=6.02, $\mathrm{p}=0.028)$. The resistances of the other component of the stem were generally small and, except for $R_{M S}$, were not significantly different between the clones. Root resistances $\left(R_{r}\right)$ were significantly larger than stem resistances in both clones $(\mathrm{p}=0.002)$. The proportional contribution of the shoots and roots differed between the clones (Table 2). In GU210, the roots contributed for over $80 \%$ of the total resistance, while in TAG14, this contribution was less than $60 \%$.

Table 2. Proportional contributions of individual components to the total plant hydraulic resistances of three months old saplings of the clones GU210 and TAG14.

\begin{tabular}{|c|c|c|c|c|c|c|}
\hline \multicolumn{7}{|c|}{ Contribution of hydraulic resistances (\%) expressed per unit leaf area } \\
\hline Clones & $\mathbf{R}_{\mathbf{L}}$ & $\mathbf{R}_{\mathbf{P}}$ & $\mathbf{R}_{\mathrm{LBB}}$ & $\mathbf{R}_{\mathrm{MS}}$ & $\mathbf{R}_{\mathrm{S}}$ & $\mathbf{R}_{\mathbf{r}}$ \\
\hline GU210 & $10.50 \pm 0.68$ & $0.30 \pm 0.07$ & $5.47 \pm 0.22$ & $2.50 \pm 0.13$ & $18.80 \pm 0.74$ & $81.20 \pm 0.74$ \\
\hline TAG14 & $21.80 \pm 2.59$ & $0.68 \pm 0.23$ & $9.51 \pm 0.62$ & $9.31 \pm 1.59$ & $41.30 \pm 2.58$ & $58.70 \pm 2.58$ \\
\hline
\end{tabular}

\section{DISCUSSION}

Total leaf areas of the plants of the two clones were not significantly different from each other (Table 1). However, it has been reported that leaf areas of different clones of 2 and 3 months old Eucalyptus globulus (Labill.) (Pita \& Pardos, 2001), and 5 months old Eucalyptus camaldulenesis Dehnh. (Farrell et al., 1996) were significantly different. However, both total leaf area and specific leaf area (SLA) were recorded to be the same in 31/2 years old saplings of Scots pine and Sitka spruce (Jackson et al., 1995a). SLA can be brought about by a change in several leaf characteristics, both chemical and anatomical (Lambers \& Poorter, 1992). The SLA of GU210 was greater than that of TAG14. However, despite the relationship that has been shown to exist between SLA and photosynthetic rates (Pereira et al., 1992), there was no significant difference in maximal net $\mathrm{CO}_{2}$ assimilation rates between the clones. Similar results have been recorded for different clones of $E$. globulus (Pita \& Pardos, 2001). Changes in SLA may also be brought about by differences in the 
veinal transport system of the leaf (Lambers \& Poorter, 1992). $R_{\mathrm{L}}$ of GU210 was lower than that of TAG14, possibly suggesting less allocation of biomass to transport tissue in GU210 which could lead to higher SLA.

Total shoot mass, plant height, and stem over-bark diameter of TAG14 were greater than those of GU210. These results are consistent with those of Pita \& Pardos (2001) who found significant differences in these parameters between potted 2 and 3 month old specimens of three clones of $E$. globulus. In contrast, no significant differences in dry matter accumulation have been observed 6 month old potted specimens of three different clones of E. globulus (Osorio et al., 1998). However, February et al. (1995) have recorded that there were no differences in total whole plant dry weight and stems diameter between 16 month old $E$. grandis and the E. grandis x camaldulensis in large pots. It appears that inter-clonal differences apparent in young specimens disappear with age in potted trials.

The values of $\psi_{\mathrm{L}}$ for both clones were lower than those reported by Vander Willigen \& Pammenter (1998) for 7 year-old trees, suggesting that establishing saplings may be more prone to water deficits than mature trees.

Although $\mathrm{g}_{\mathrm{s}}, \mathrm{E}$ and leaf water potential differed slightly between the clones, the lower $\mathrm{g}_{\mathrm{s}}$ in GU210 did not appear to limit $\mathrm{CO}_{2}$ assimilation. Despite this lack of difference in photosynthetic rates, TAG14 produced higher above ground biomass than GU210. Similar results have been reported for field grown E. globulus in two watering treatments (Pereira et al., 1989, 1992). It has also been reported that in potted seedlings of E. pauciflora, water stress has initially caused partial stomatal closure without any decline in the net $\mathrm{CO}_{2}$ assimilation rate or intercelluar $\mathrm{CO}_{2}$ partial pressure but later had affected these under severe water stress (Kirschbaum, 1987). This apparent lack of stomatal limitation of $\mathrm{CO}_{2}$ assimilation is supported by the observation of Clearwater \& Meinzer (2001). They have reported that in a fertilizer treatment the leaf nitrogen concentration and photosynthetic capacity in field grown E. grandis have increased although there was no change in stomatal behaviour. Pereira et al. (1992) have reported that an increase in foliar nitrogen concentration has increased the photosynthetic capacity of field grown E. globules. Howevr, this aspect was not examined in this present study.

According to Osorio et al. (1998), water deficits rather than leaf nitrogen levels are more important in delaying growth. According to Sheriff (1992), very small differences in the rates of $\mathrm{A}$ have the potential to produce large differences in biomass over time. It is possible that the slightly higher midday net $\mathrm{CO}_{2}$ assimilation rate of TAG14 was adequate to accumulate more carbon than in GU210. The clone TAG14 
Growth characteristics

showed greater above-ground biomass with highest $\mathrm{g}_{s}$, and GU210 had lower $\mathrm{g}_{\mathrm{s}}$ and presumably used less water. It was not possible to measure total water utilization by the plants in the present study and therefore, it was not possible to measure water utilizing efficiency (WUE).

The root hydraulic resistances normalised by leaf area ( $\mathrm{R}_{\mathrm{r}^{*} \mathrm{LA}}$, absolute root hydraulic resistance multiplied by total leaf area) were higher than shoot resistances normalised by leaf area $\left(\mathrm{R}_{\mathrm{s}^{*} \mathrm{LA}}\right.$, absolute shoot hydraulic resistance multiplied by total leaf area), comprising $59 \%$ of total plant resistance in TAG14 and $81 \%$ in GU210. Commonly, root and shoot resistances are approximately equal, or root resistances are somewhat lower than shoot resistances (Nardini \& Tyree, 1999; Brodribb \& Hill, 2000). However, there are few reported occurrences of $R_{r}$ constituting a large proportion of $\mathrm{R}_{\text {Plant }}$ (Nardini \& Pitt, 1999; Brodribb \& Hill, 2000). The value for $\mathrm{R}_{\text {Plant }}$ recorded for GU210 in this study appears to be the highest reported. In a preliminary field study at a different mesic site, 3 month old samples of a different Eucalyptus grandis x urophylla clone (GU21) had also shown high proportion of whole plant resistance $(82 \%)$ contributed by the roots (Unpublished data of the author). This suggests that high root resistances may be a genetic characteristic in $E$. grandis $\mathrm{x}$ urophylla hybrids.

The values of $R_{r^{*} L A}$ obtained in this study are very similar to the values reported for Eucalyptus regnans by Brodribb \& Hill (2000). The values reported here for the GU210 and TAG14 tend to be at the low end of the range reported for other species (Nardini \& Tyree, 1999; Tsuda \& Tyree, 1997; Brodribb \& Hill, 2000), suggesting that the roots of these clones are able to conduct water efficiently.

Scaling of shoot hydraulic conductances to leaf area $\left(\mathrm{K}_{\mathrm{S} / \mathrm{LA}}\right)$ and to total shoot dry mass $\left(\mathrm{K}_{\mathrm{S} / \mathrm{tsdw}}\right)$ gave the same trend for both clones. The fact that GU210 had the higher normalised shoot hydraulic conductance $\left(\mathrm{K}_{\mathrm{S} / \mathrm{tsdw}}\right)$ suggests that this clone spends less carbon to provide an efficient pathway than does TAG14, which is in accordance with their different shoot dry masses. A high shoot conductance should ensure rapid equilibration of the shoot with soil water at night, which would promote rapid growth by maintaining high values of meristem water potential (Nardini \& Salleo, 2000). In the present study, the higher shoot conductances recorded in GU210 were in fact associated with lower leaf water potential, stomatal conductances and above ground growth when compared to TAG14. The higher shoot conductances of GU210 than that of TAG14 is possibly a trait associated with strong apical control as it is thought to hydraulically favour the faster growing leader (Tyree \& Ewers, 1996). However, a high shoot conductance alone will not ensure rapid equilibration with the soil if root conductance is low and the water cannot get into the stem quickly. This 
was evident from the results that the higher $\mathrm{K}_{\mathrm{r} / \mathrm{LA}}$ of TAG14 permitted sufficient water uptake from the soil to maintain lower leaf level water stress with higher $\mathrm{g}_{\mathrm{s}}$ than in GU210. Tyree et al. (1993) also suggested that low water potentials can cause reduced cell expansion, wall synthesis, protein synthesis, $\mathrm{g}_{s}$ and photosynthesis and an increase xylem dysfunction by cavitation events.

Whole plant hydraulic conductances will depend to some extent on xylem $\psi$, and when xylem $\psi$ falls below the cavitation threshold, whole plant hydraulic conductances will decrease as a consequence of the xylem embolism (Tyree and Sperry, 1989). Although the difference in maximum whole plant hydraulic conductances between the two clones measured using the HPFM $\left(K_{P / L A}=1 /\left(1 / K_{S}\right.\right.$ $\left.+1 / K_{r}\right)$ ) was not significant $(P=0.089$; Fig. $4, C)$, leaf physiology and above ground biomass production appear to have a correlation with this difference. Similarly, the whole plant hydraulic conductances estimated from the relationship between $E$ and $\psi_{\mathrm{L}}$ were not significantly different in the two clones (Fig. 2). However, both methods indicated a higher conductance in TAG14 than in GU210. In keeping with this, midday $\psi_{\mathrm{L}}, \mathrm{g}_{\mathrm{s}}$ and $\mathrm{E}$ were higher in TAG14 than in GU210 (Fig.1), and therefore total above-ground biomass of TAG14 was higher than that of GU210 (Table 1). These results are in accordance with those of Vander Willigen \& Pammenter (1998), who showed that 7 years old trees on mesic sites had higher biomass and branch leaf specific conductivity than those growing on xeric sites. The relationship between $\mathrm{E}$ and $\psi_{\mathrm{L}}$ for TAG14 was not linear particularly at high transpiration rates. This suggests the possible involvement of an hydraulic capacitance somewhere in the water transport system from soil to leaf that releases stored water at low water potentials, giving rise to an apparent increase in hydraulic conductance at high values of E. Similarly, Koide (1985) and Tsuda \& Tyree (2000) observed that hydraulic conductances, estimated by the evaporative flux (EF) method (slope of the relationship between $\psi_{\mathrm{L}}$ and $\mathrm{E}$ ), increased with increase of $\mathrm{E}$ in sunflower plant. In this method, transpiration and leaf water potential were measured almost instantaneously on the same leaf, and therefore, a 1:1 relationship between these two values had been obtained. However, this method cannot give a complete measure of whole plant conductance as the values of both $\mathrm{E}$ and $\psi$ vary from leaf to leaf.

The vulnerability of the xylem to cavitation, in terms of $\psi_{\mathrm{L}}$ triggering xylem cavitation, was estimated by two methods; firstly, using the mean of the water potentials corresponding to acoustic emissions between $5 \%$ and $10 \%$ of the total ( $\psi_{\mathrm{CAv}}, \mathrm{cUAE}, \%$ ) (Nardini \& Salleo, 2000; Salleo et al., 2000 and Nardini et al., 2001) and secondly, using the intersection of lines fitted to data at low and high cumulative emissions (Fig. 3.B). Both methods showed that $\psi_{\mathrm{L}}$ triggering xylem 
cavitation was higher in TAG14 than in GU210. Also, $\mathrm{EPH}_{\max }$ occurred at a higher $\psi_{\mathrm{L}}$ for TAG14 than for GU210, although these values were not significantly different. The values calculated using the intersection method (-1.32 MPa for TAG14 and -1.42 $\mathrm{MPa}$ for GU210) were similar to the values of $\psi$ corresponding to $50 \%$ loss of conductivity measured hydraulically on branches of seven year old field grown trees of related clones (-1.31 MPa for TAG5 and -1.50 MPa for GU21) by Vander Willigen \& Pammenter (1998). The patterns between clonal families were consistent in the two studies, indicating the importance of genotype in determining the vulnerability to cavitation. Twelve month old potted saplings of the clone GU210 were more susceptible to xylem cavitation ( $-0.73 \mathrm{MPa})$ (unpublished data of the author) than 3 months old field grown saplings $(-1.38 \mathrm{MPa})$. This suggests that vulnerability to cavitation varies among potted and field saplings. Ray \& Sinclair (1998) have shown differences of growth and physiological parameters due to variation in pot size.

The concept of safety versus efficiency of the hydraulic supply system has been discussed by many authors. The general hypothesis is that the more efficient wide conduits are more vulnerable to cavitiation (Zimmermann, 1983; Tyree et al., 1994a; Lo Gullo et al., 1995), and are more difficult to refill (Jaquish \& Ewers, 2001). However, according to the 'air-seeding' hypothesis, the size of the pit membrane pore determines the vulnerability to cavitation. In the Eucalyptus clones investigated here, the hydraulic conductivity of the stem was lower and the vulnerability to cavitation was higher in TAG14, compared to GU210. Similar negative correlations have been reported in some Quercus species (Cochard et al., 1992a) and in seedlings of Douglas fir grown with different water availabilities (Kavanagh et al., 1999). This was attributed to the different proportions of early and late wood in the seedlings; however, such an effect is unlikely in the Eucalyptus clones used in the present study, as Eucalyptus spp. are diffuse porous, and the plants studied were only three months old. TAG14 showed more profuse branching than GU210 and therefore, the junction constrictions could have reduced shoot conductivity. It has been suggested that vessel vulnerability is coupled to the prevailing vessel $\psi$, and the results of the present study indicate that GU210 operates at lower $\psi$ (Fig. 1A) and is less vulnerable to cavitation (Fig. 3) than TAG14.

A function of stomata is to reduce $\mathrm{E}$ to levels that prevent $\psi_{\mathrm{L}}$ being reduced to the extent so that massive cavitation and runaway xylem embolism cycles do not occur (Jones \& Sutherland, 1991; Alder et al., 1996; Sparks \& Black, 1999; Salleo et $a l ., 2000)$. For both clones studied here, maximal stomatal conductance $\left(\mathrm{g}_{\mathrm{s} \max }\right)$ and maximal rate of cavitation $\left(\mathrm{EPH}_{\max }\right)$ occurred at the same time (mid morning), but at 
different levels of leaf water potential (Fig. 3C). Thereafter, $g_{s}$ decreased as did the rate of cavitation, although leaf water potential continued to decline. The $\psi$ values corresponding to the initiation of stomatal closure were in fact lower than those corresponding to the initiation of cavitation events (Fig. 3). Thus, stomatal control was not adequate to prevent substantial cavitations. This indicates considerable redundancy in the hydraulic supply system in the main stem where cavitations were measured. Interestingly, TAG14 had lower shoot hydraulic conductivity than GU210, and the decrease in $\mathrm{g}_{s}$ in TAG14 following $\mathrm{EPH}_{\max }$ was $20 \%$, compared to only $7 \%$ in GU210. This perhaps indicates that redundancy in the stem was less in TAG14 than in GU210 and consequently TAG14 is more sensitive to mild changes in $\psi_{\mathrm{L}}$, and therefore, may be more drought sensitive than GU210.

Stomata have been reported to maintain $\psi_{\mathrm{L}}$ above the value of the $\psi$ triggering xylem cavitation in a number of species (Saliendra et al., 1995; Hacke \& Sauter, 1996; Irvine et al., 1998; Bond \& Kavanagh, 1999; Brodribb \& Hill, 2000). In contrast, the midday $\psi_{\mathrm{L}}$ measured in this study was lower than the $\psi$ triggering cavitations ( $\psi_{\mathrm{CAV}}, \mathrm{CUAE}, \%$ ), and considerable cavitation events did occur (Fig. 3). Similarly, there are other reports of $\psi_{\mathrm{L}}$ being lower than those triggering cavitations (Jackson et al., 1995a, 1995 b; Hacke \& Sauter, 1995; Sparks \& Black, 1999). Low g would prevent high tensions in the xylem water column and reduces cavitations as documented by Jones \& Sutherland (1991), Alder et al. (1996), Sparks \& Black (1999) and Salleo et al. (2000). In fact, the higher $\mathrm{g}_{\mathrm{s}}$ in TAG14 than in GU210 was associated with higher vulnerability, which is in contrast to the predictions. However, cavitation events will release water into the transpiration stream, and if refilling can occur overnight, this effect could avoid low $\psi_{\mathrm{L}}$ during times of high $\mathrm{E}$. In accordance with this, the relationship between $\mathrm{E}$ and $\psi_{\mathrm{L}}$ in TAG14 was not linear (Fig. 2) suggesting a possible capacitance effect. According to Salleo et al. (2000), conduits of plants growing in wet soil and undergoing diurnal embolisms, can completely recover at night so that shoot cavitation remains as a transient and completely reversible phenomenon.

Positive $\mathrm{P}_{\mathrm{r}}$ is a mechanism by which embolized xylem conduits of small plants can be refilled (Lopez-Portillo et al., 2000). Positive $\mathrm{P}_{\mathrm{r}}$ values in woody species were reported to range from $3 \mathrm{kPa}$ (Sperry, 1993) to $225 \mathrm{kPa}$ (Lopez-Portillo et al., 2000). Van Der Meer et al. (1999) reported positive $\mathrm{P}_{\mathrm{r}}$ in Eucalyptus regnans. Both Eucalyptus clones used $\mathrm{n}$ this study exhibited positive $\mathrm{P}_{\mathrm{r}}$, both during night and at midday. Positive $\mathrm{P}_{\mathrm{r}}$ values in midday were also reported by Sperry (1993). Theoretically, a pressure of $10 \mathrm{kPa}$ is required to raise a water column by $1 \mathrm{~m}$ and therefore, the pressures developed by the two clones used in this study (41 to $62 \mathrm{kPa}$ ) 
Growth characteristics

were more than adequate to lift a water column to the height of the plants $(0.7 \mathrm{~m})$ and this could be the processes by which embolisms are refilled. It has been conventionally accepted that refilling of embolized vessels by $\mathrm{P}_{\mathrm{r}}$ occurs during the night, when E is virtually absent. However, Canny (1997), McCully et al. (1998), and McCully (1999), using cryo-scanning electron microscopy, observed embolism repair in vessels, concurrently with maximum transpiration rate. Thus, the xylem recovery in any part of the plant concurrently with maximum E rate may not be ruled out. Although significant only with night values, GU210 tended to have higher $P_{r}$ than TAG14, perhaps indicating that GU210 could refill embolized vessels more efficiently than TAG14. Coupled with the lower vulnerability of GU210, this could contribute to a greater water stress tolerance by GU210, as opposed to the possibility of TAG14 avoiding low leaf water potentials by releasing capacitance water through cavitation events.

\section{ACKNOWLEDGEMENTS}

The authors wish to thank the School of Life and Environmental Sciences of the University of Natal and the Mondi Forests of Hilton, South Africa for the supply of Eucalyptus spp. ramets used in the field trial with partial financial support, and Prof. M. T. Tyree of the United States Department of Agriculture Forest Service, Burlington, Vermont, USA for providing the high-pressure flow meter.

\section{REFERENCES}

Alder, N.N., J.S. Sperry \& W.T. Pockman 1996. Root and stem embolism, stomatal conductance, and leaf turgor in Acer grandidentatum populations along a soil moisture gradient. Oecologia 105: 293-301.

Becker, P., F.C. Meinzer \& S.D. Wullschleger 2000. Hydraulic limitation of tree height: a critique. Functional Ecology 14: 4-11.

Bond, B.J. \& K.L. Kavanagh 1999. Stomatal behavior of four woody species in relation to leaf specific hydraulic conductance and threshold water potential. Tree Physiology 19: 503-510.

Brodribb, T. \& T.S. Field 2000. Stem hydraulic supply is linked to leaf photosynthetic capacity: evidence from new caledonian and tasmanian rainforests. Plant, Cell and Environment 23:1381-1388. 
Brodribb, T. \& R.S. Hill 2000. Increases in water potential gradient reduce xylem conductivity in whole plants: evidence from a low-pressure conductivity method. Plant Physiology 123: 1021-1028.

Canny, M.J. 1997. Vessels contents during transpiration: embolism and refilling. American Journal of Botany 84: 1217-1222.

Clearwater, M.J. \& F.C Meinzer 2001. Relationships between hydraulic architecture and leaf photosynthetic capacity in nitrogen-fertilized Eucalyptus grandis trees. Tree Physiology 21:683-690.

Cochard, H., N. Breda, A. Granier \& G. Aussenac 1992. Vulnerability to air embolism of three European oak species (Quercus petraea (Matt) Liebl, $Q$. pubescens Willd, Q. robur L). Annales Des Sciences Forrestieres 49: 225 233.

Farrell, R.C.C., D.T. Bell, K. Akilan \& J.K. Marshall 1996. Morphological and physiological comparisons of clonal lines of Eucalyptus camaldulensis: responses to drought and waterlogging. Australian Journal of Plant Physiology 23: 497-507.

February, E.C., W.D. Stock, W.J. Bond \& D.J. Le Roux 1995. Relationships between water availability and selected vessel characteristics in Eucalyptus grandis and two hybrids. IAWA Journal 16: 269-276.

Franks, P.J., A. Gibson \& E.P. Bachelard 1995. Xylem permeability and embolism susceptibility in seedlings of Eucalyptus camaldulensis Dehnh. from two different climatic zones. Australian Journal of Plant Physiology 22: 15-21.

Hacke, U. \& J.J. Sauter 1996. Drought induced xylem dysfunction in petioles, branches and roots of Populus balsamifera (L.) and Alnus glutinosa (L.) Gaertn. Plant Physiology 111: 413-417.

Hacke, U. \& J.J. Sauter 1995. Vulnerability of xylem to embolism in relation to leaf water potential and stomatal conductance in Fagus sylvatica, F. purpurea and Populus balsamifera. Journal of Experimental Botany 46: 1177-1183. 
Growth characteristics

Hubbard, R.M., B.J. Bond and M.G. Ryan 1999. Evidence that hydraulic conductance limits photosynthesis in old Pinus ponderosa trees. Tree Physiology 19:165-172.

Irvine, J., M.P. Perks, F. Magnani \& J.Grace 1998. The response of Pinus sylvestris to drought: stomatal control of transpiration and hydraulic conductance. Tree Physiology 18: 393-402.

Jackson, G.E., J. Irvine \& J. Grace 1995a. Xylem cavitation in scots pine and sitka spruce saplings during water stress. Tree Physiology 15: 783-790.

Jackson, G.E., J. Irvine \& J. Grace 1995b. Xylem cavitation in two mature Scots pine forests growing in a wet and a dry area of Britain. Plant, Cell and Environment 18: 1411-1418.

Jaquish, L.L. \& F.W. Ewers 2001. Seasonal conductivity and embolism in the roots and stems of two clonal ring-porous trees, Sassafras albidum (Lauraceae) and Rhus typhina (Anacardiaceae). American Journal of Botany 88: 206-212.

Jones, H.G. \& R.A. Sutherland 1991. Stomatal control of xylem embolism. Plant, Cell and Environment 14: 607-612.

Kavanagh, K.L., B.J. Bond, S.N. Aitken, B.L. Gartner \& S. Knowe 1999. Shoot and root vulnerability to xylem cavitation in four populations of Douglas-fir seedlings. Tree Physiology 19: 31-37.

Kirschbaum, M.U.F. 1987. Water stress in Eucalyptus pauciflora: comparison of effects on stomatal conductance with effects on the mesophyll capacity for photosynthesis and investigation of a possible involvement of photoinhibition. Planta 171: 466-473.

Koide, R. 1985. The nature and location of variable hydraulic resistance in Helianthus anmuus L. (Sunflower). Journal of Experimental Botany 36: 14301440 .

Kramer, P.J. \& J.S. Boyer 1995. Water Relations of Plants and Soils. Second edition. Academic Press, CA. 
Lambers, H. \& H. Poorter 1992. Inherent variation in growth rate between higher plants: a search for physiological causes and ecological consequences. Advances in Ecological Research 23. Academic Press, CA.

Le Roux, J.J. \& J. Van Staden 1991. Micro-propagation and tissue culture of Eucalyptus: a review. Tree Physiology 9: 435-77.

Lo Gullo, M.A., S. Salleo, E. C. Piaceri \& R. Rosso 1995. Relations between vulnerability to xylem embolism and xylem conduit dimensions in young trees of Quercus cerris. Plant, Cell and Environment 18: 661-669.

Lopez-Portillo, J., F.W. Ewers, G. Angeles \& J.B Fisher 2000. Hydraulic architecture of Monstera acuminata: evolutionary consequences of the hemiepiphytic growth form. New Phytology 145: 289-299.

McCully, M.E. 1999. Root xylem embolisms and refilling: relation to water potentials of soil, roots and leaves and osmotic potentials of root xylem sap. Plant Physiology 119: 1001-1008.

McCully, M.E., C.X. Huang \& L.E.C. Ling 1998. Daily embolism and refilling of xylem vessels in the roots of field -grown maize. New Phytology 138: 327342.

Mencuccini, M. \& J. Grace 1996. Developmental patterns of above ground hydraulic conductance in a scots pine (Pinus sylvestris L.) age sequence. Plant, Cell and Environment 19: 939-948.

Mulin, T.J. \& Y.S. Park 1992. Estimating genetic gains from alternative breeding strategies for clonal forestry. Canadian Journal of Forestry Research 22:1423.

Nardini, A. \& F. Pitt 1999. Drought resistance of Quercus pubescens as a function of root hydraulic conductance, xylem embolism and hydraulic architecture. New Phytology 143: 485-493.

Nardini, A. \& M.T. Tyree 1999. Root and shoot hydraulic conductance of seven Quercus species. Annales Des Sciences Forrestieres 56: 371-377. 
Growth characteristics

Nardini, A. \& S. Salleo 2000. Limitation of stomatal conductance by hydraulic traits: sensing or preventing xylem cavitation? Trees 25: 14-24.

Nardini, A., M. T. Tyree \& S. Salleo 2001. Xylem cavitation in the leaf of Prumus laurocerasus and its impact on leaf hydraulics. Plant Physiology 125: 17001709.

Olbrich, B.W., D. Le Roux, A.G. Poulter, W.J. Bond \& W.D. Stock 1993. Variation in water use efficiency and $\delta^{13} \mathrm{C}$ levels in Eucalyptus grandis clones. Journal of Hydrology 150: 615-633.

Osorio, J., M.L. Osorio, M.M. Chaves \& J.S. Pereira 1998. Water deficits are more important in delaying growth than in changing patterns of carbon allocation in Eucalyptus globulus. Tree Physiology 18: 363-373.

Pereira, J.S., S. Linder, M.C. Araujo, H. Pereira, T. Ericsson, N. Borralho \& L. Leal 1989. Optimization of biomass production in Eucalyptus globulus plantations: a case study. In: Biomass Production by Fast-growing Trees (Pereira, J.S. \& J.J Landsberg eds), pp. 101-121, Kluwer Publ., Dordrecht, The Netherlands.

Pereira, J.S., M.M. Chaves, F. Fonseca, M.C. Araujo \& F.Torres 1992. Photosynthetic capacity of leaves of Eucalyptus globulus (Labill.) growing in the field with different nutrient and water supplies. Tree Physiology 11: 381389.

Pita, P. \& J.A. Pardos 2001. Growth, leaf morphology, water use and tissue water relations of Eucalyptus globulus clones in response to water deficit. Tree Physiology 21: 599-607.

Ray, J.D. \& T.R. Sinclair 1998. The effect of pot size on growth and transpiration of maize and soybean during water deficit stress. Journal of Experimental Botany 49:1381-1386.

Ryan, M.G. \& B.J. Yoder 1997. Hydraulic limits to tree height and tree growth. BioScience 47: 235-242. 
Saliendra, N.Z., J.S. Sperry \& J.P. Comstock 1995. Influence of leaf water status on stomatal response to humidity, hydraulic conductance, and soil drought in Betula occidentalis. Planta 196: 357-366.

Salleo, S., A. Nardini, F. Pitt \& M.A. Lo Gullo 2000. Xylem cavitation and hydraulic control of stomatal conductance in Laurel (Laurus nobilis L.). Plant, Cell and Environment 23: 71-79.

Scholander, P.G., H.T. Hammel \& E.D. Bradstreet 1965. Sap pressure in vascular plants. Science 148: 339-346.

Schultz, H.R. \& M.A. Matthews 1988. Resistance to water transport in shoots of Vitis vinifera $\mathrm{L}$. relation to growth at low water potential. Plant Physiology 88: 718-724.

Sheriff, D.W. 1992. Roles of carbon gain and allocation in growth at different nitrogen nutrition in Eucalyptus camaldulensis and Eucalyptus globulus seedlings. Australian Journal of Plant Physiology 19: 637-652.

Sommer, H.E. \& H.Y. Wetzstein 1984. Crop species. In: Plant cell culture. Vol 3: Hardwoods (Ammirato, P.V., D.A. Evans, W. R. Sharp \& Y. Yamaha eds), Macmillan Publishing Company, New York London.

Sparks, J.D. \& R.A. Black 1999. Regulation of water loss in populations of Populus trichocarpa: the role of stomatal control in preventing xylem cavitation. Tree Physiology 19: 453-459.

Sperry, J.S. 1993. Winter embolism and spring recovery. In: Water Transport in Plants under Climatic Stress (Borghetti, M., J. Grace \& A. Raschi eds), pp. 86-98, Cambridge University Press, Cambridge.

Sperry, J.S. \& W.T. Pockman 1993. Limitation of transpiration by hydraulic conductance and xylem cavitation in Betula occidentalis. Plant, Cell and Environment 16: 279-287.

Sperry, J.S., N. Holbrook, M.H. Zimmermann \& M.T. Tyree 1987. Spring filling of xylem vessels in wild grapevine. Plant Physiology 83: 414-417. 
Growth characteristics

Tsuda, M. \& M.T. Tyree 1997. Whole-plant hydraulic resistance and vulnerability segmentation in Acer saccharinum. Tree Physiology 17: 351-357.

Tsuda, M. \& M.T. Tyree 2000. Plant hydraulic conductance measured by the highpressure flow meter in crop plants. Journal of Experimental Botany 51: 823828.

Tyree, M.T. \& J.S. Sperry 1989. Vulnerability of xylem cavitation and embolism. Annual Review of Plant Physiology and Molecular Biology 40:19-38.

Tyree, M.T., B. Sinclair, P. Lu \& A. Granier 1993. Whole shoot hydraulic resistance in Quercus species measured with a new high-pressure flow meter. Annales Des Sciences Forrestieres 50: 417-423.

Tyree, M.T., S. D. Davis \& H. Cochard 1994a. Biophysical perspectives of xylem evolution: Is there a tradeoff of hydraulic efficiency for vulnerability to dysfunction? IAWA Journal 15: 335-360.

Tyree, M.T., S. Yang, P. Cruiziat \& B. Sinclair 1994b. Novel methods of measuring hydraulic conductivity of tree roots system and interpretation using AMAIZED: a maize-root dynamic model for water and solute transport. Plant Physiology 104:189-199.

Tyree, M.T. \& F.W. Ewers 1996. Hydraulic Architecture of woody tropical plants. In: Tropical Forest Plant Eco-physiology (Mulkey, S.S., R.L. Chazdon and A.P. Smith eds), pp. 217-243, Chapman and Hall. New York.

Tyree, M.T., S. Patino, J. Bennink \& J. Alexander 1995. Dynamic measurements of root hydraulic conductance using a high-pressure flow meter in the laboratory and field. Journal of Experimental Botany 46: 83-94.

Tyree, M.T., V. Velez \& J.W. Dalling 1998. Growth dynamics of root and shoot hydraulic conductance in seedlings of five neotropical tree species: scaling to show possible adaptation to differing light regimes. Oecologia 114: 293-298. 
Van Der Meer, P.J., P. Dignan \& A.G. Saveneh 1999. Effect of gap size on seedling establishment, growth and survival of Eucalyptus regnans F. Muell at three years in mountain ash forest in Victoria, Australia. Forest Ecology Management 117:33-42.

Van Wyk, G. 1990. Genetic improvement of timber yield and wood quality in Eucalyptus grandis (Hill) Maiden. South African Forestry Journal 153: 1-11.

Vander Willigen, C., \& N.W. Pammenter 1998. Relationship between growth and xylem hydraulic characteristics of clones of Eucalyptus spp. at contrasting sites. Tree Physiology 18: 595-600.

Yang, S. \& M.T. Tyree 1994. Hydraulic architecture of Acer saccharum and A. rubrum: comparison of branches to whole trees and the contribution of leaves to hydraulic resistance. Journal of Experimental Botany : 45 : 179-186.

Zimmermann, M.H. 1983. Xylem Structure and the Ascent of Sap. Springer-Verlag, Berlin. pp 1-99. 